\title{
Food Insecurity and Anthropometry in Adolescents: A Literature Review
}

\author{
Nikmah Utami Dewi ${ }^{1,2}$, Nurulfuadi ${ }^{2}$, Ummu Aiman $^{2}$, Diah Ayu Hartini ${ }^{2}$, Fendi Pradana ${ }^{2}$, Bohari Bohari ${ }^{2 *}$ \\ ${ }^{1}$ Department of Community Nutrition, IPB University, Bogor, Indonesia; ${ }^{2}$ Nutrition Department, Faculty of Public Health, \\ Tadulako University, Palu, Indonesia
}

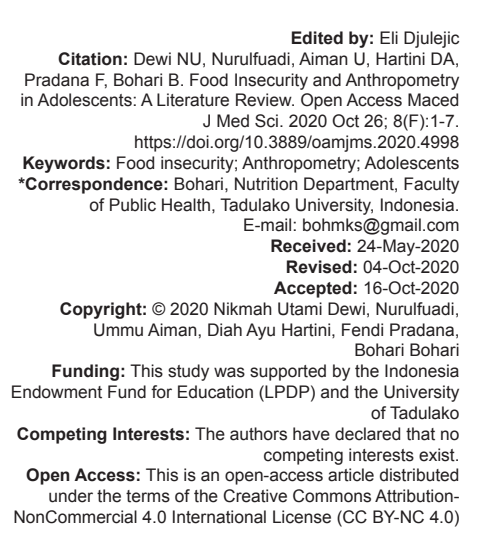

Introduction

Food security is a state when all people, at all times, have physical, social, and economic access to sufficient, safe, and nutritious food to meet their dietary needs according to their preferences for an active and healthy life [1]. The pillars of food security are food availability, food access, and food utilization. These three pillars are closely related. If one aspect is not fulfilled, it may affect other aspects and thereby encouraging food insecurity [2]. Food unavailability and difficult access to food have the potential to increase the risk of malnutrition in various life cycles, including in children, adults, and adolescent groups [3].

Adolescence is a young age group at the age of 10-19 years [4], and the number of adolescents reaches $18 \%$ worldwide [5]. The nutritional requirements in adolescents increase rapidly due to the rapid increase in biological or psychological growth, either in boys or girls [6]. The second period of a growth spurt after infancy occurs in adolescence [7]. Besides that, the highest bone mass reserve is also found in adolescence [8]. Adolescent nutrition will affect the health of adolescents in the present and future, future labor productivity, and improvement in the generation that will be born [9], [10], [11], [12].

Malnutrition is a major problem that contributes to decreased growth [13]. Manifestations of malnutrition can be observed in the nutritional status of adolescents. Nutritional status is the level of nutrients related to normal metabolism in the body [14]. The high and low intake of nutrients and their use in the body have an impact on nutritional status [15]. In adolescents, nutritional status can be determined by using anthropometric indicators, such as body mass index for age (BMI-for-age) and height-for-age [16]. BMl-for-age and height-for-age less than or equal to -2 standard deviations (SD) are categorized as thin and short, respectively. Meanwhile, BMI-for-age more than or equal to 1SD is categorized as overweight or obese, and height-for-age more than or equal to $2 \mathrm{SD}$ is categorized as high [16].

The potential for increased risk of malnutrition in adolescents is affected by the state of food insecurity [6]. The previous review in the children group showed that half of the studies showed a positive association between food insecurity and low nutritional status, especially stunting [3]. Family food insecurity is also associated with obesity in children and adult groups [3]. A review of similar studies in the adolescent 
group could not be conducted deeper because the number of studies was still lacking.

This study aimed to evaluate the association between food insecurity and anthropometry in adolescents to provide an overview of the relationship between food security and nutritional status in adolescents globally.

\section{Methods}

\section{Data Sources and Search Methods}

The study was conducted from October to November 2019. The databases used in the literature search were PubMed, ScienceDirect, MEDLINE, and PubMed Central. Food security or food insecurity or hunger; malnutrition or obesity; adolescence or adolescents or teenagers; or teens or youth were used as keywords.

\section{Study inclusion and exclusion criteria}

The literature used in this review included articles published from 2010 to 2019 that aimed to assess the association between food security and nutritional status of adolescents, and the adolescents in the studies were defined as those aged 10-19 years [4]. Based on these criteria, 831 articles obtained from a search on PubMed, 32 articles from ScienceDirect, and 117 articles from MEDLINE were then reviewed (Figure 1). The same articles but the study objectives did not meet the established criteria, and the ones with different subject targets were excluded from the study. A total of 12 articles met the requirements, and they were used in this review.

\section{Data collection and synthesis processes}

Abstracts and articles were identified to see the compatibility with inclusion criteria. The title and contents of the article were examined so that we knew whether the article had similarities with other articles. The articles that met the inclusion criteria were coded and then summarized in Table 1 as follows: Author, design, sample, age of the subjects, nutritional status variable, confounding variables, food security measurement instruments, and results.

\section{Results}

A total of 12 studies were included in this review (Table 1). All of them used a cross-sectional design. Six studies mentioned that the sampling methods used were as follows: Two studies used the cluster sampling method [17], [18], two studies used

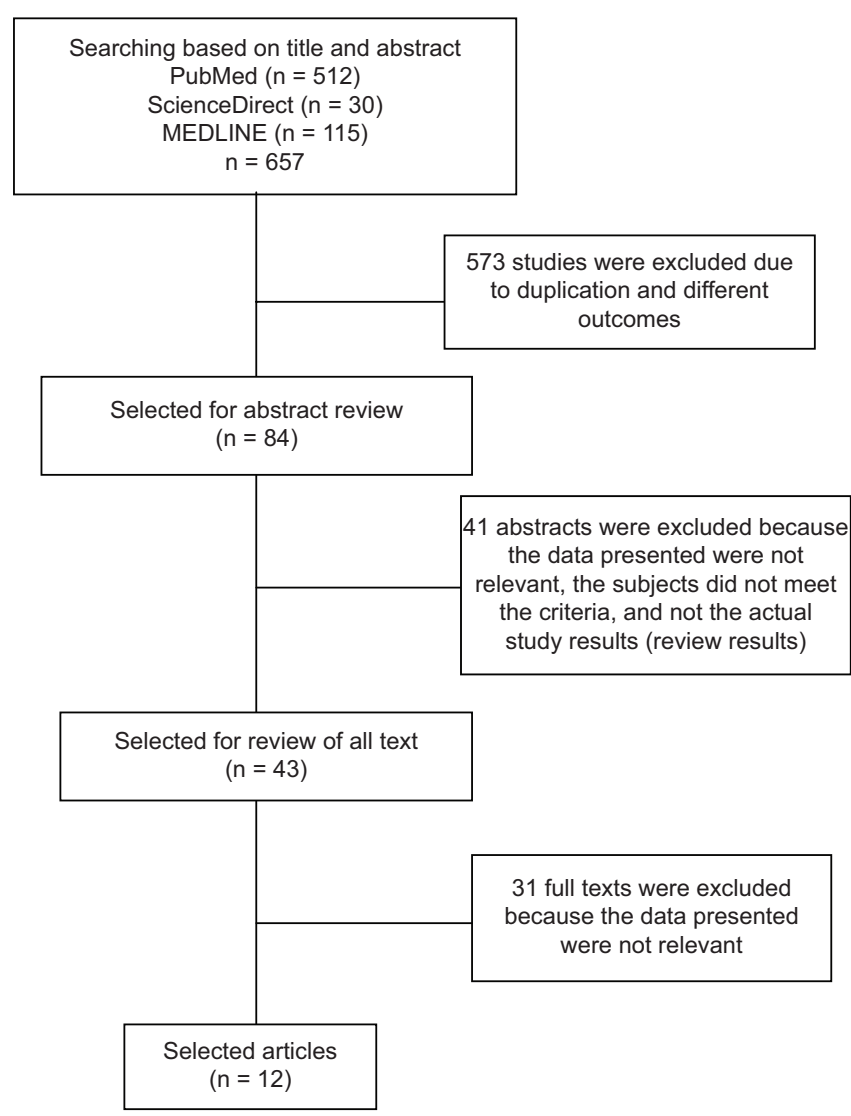

Figure 1. Literature Search and Determination Strategy

the multi-stage sampling method [19], [20], one study used a simple random sampling method [21], and one study used a combination of cluster sampling and simple random sampling (two-stage sampling) [22]. Three studies were multi-country studies conducted in developing countries or lower-middle-income countries (LMIC) [17], [18], [23] and five studies were conducted in Africa [19], [22], [24], [25], [26]. One study was conducted in Guatemala, Central America [21], one study in Canada [27], one study in the United States [28], and one study in Indonesia [20].

Nutritional status assessment in the study was conducted using the BMI, BMI-for-age, weight-for-age, height-for-age, and waist-to-height ratio (WHtR) using 2007 WHO references (16). One study assessed the nutritional status of adolescents based on BMI, one study assessed the nutritional status based on weight-for-age [27], and one study assessed the nutritional status based on WHtR [24]. Nine studies measured BMI-for-age [17], [18], [19], [20], [21], [22], [23], [24], [28] and six studies assessed the nutritional status based on the height-forage indicator [19], [20], [21], [23], [24], [25], [26].

Food insecurity was assessed by various indicators. Two studies used the question, "During the past 30 days, how often did you go hungry because there was not enough food in your home?" to determine the food-secure or food-insecure adolescents [18], [21], while two other studies used the Household Food Insecurity Access Scale (HFIAS) [19], [20]. One study used adolescents' confession whether they slept on a 

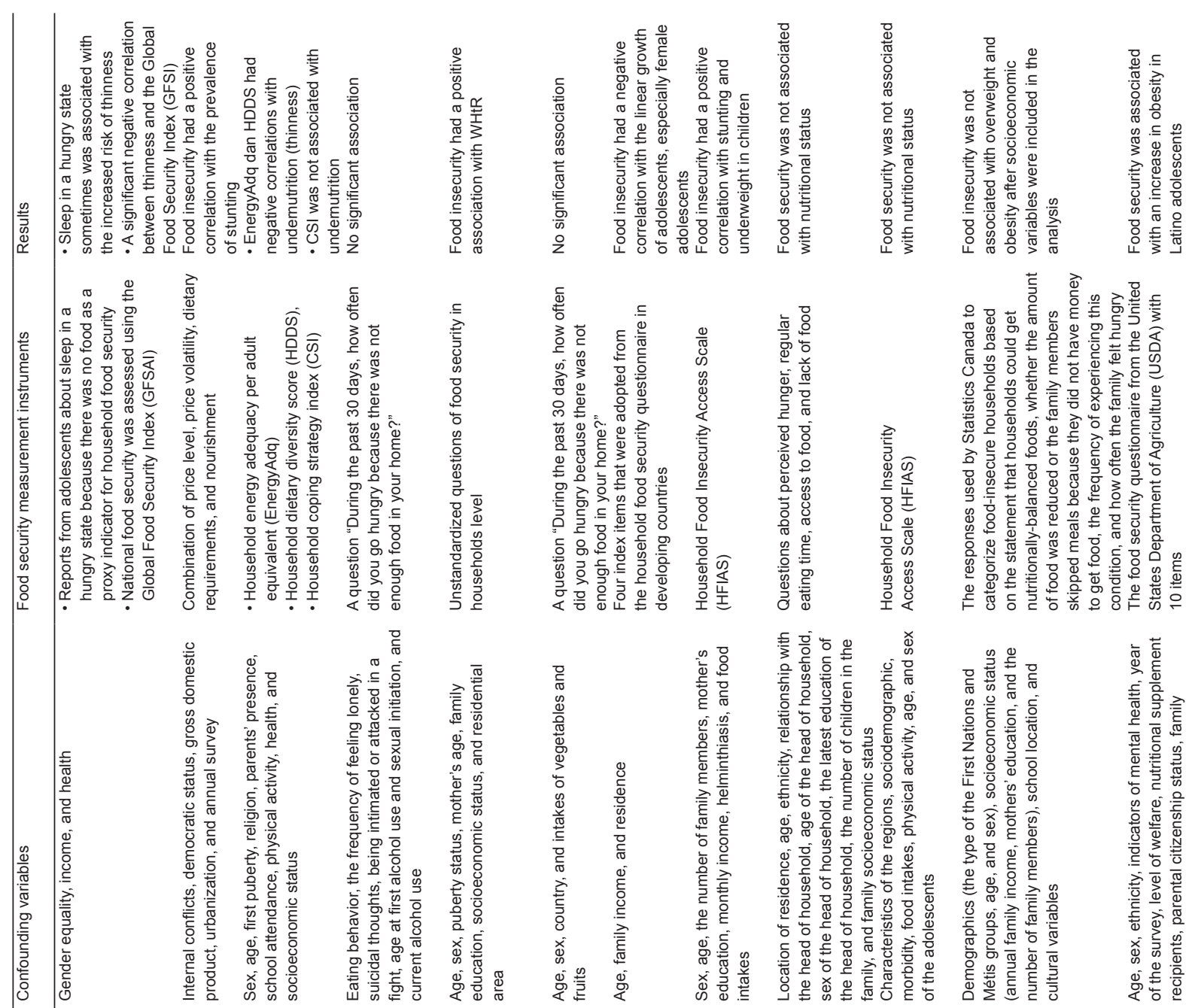

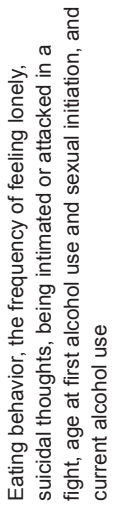

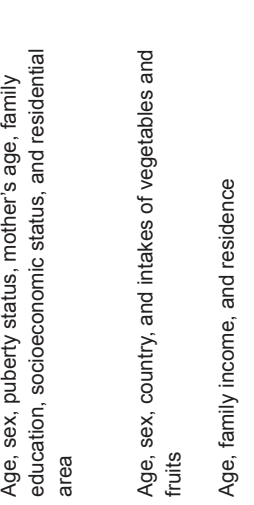

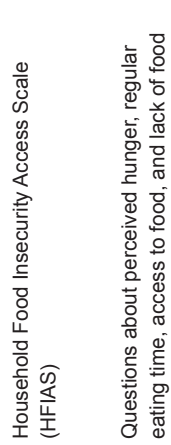
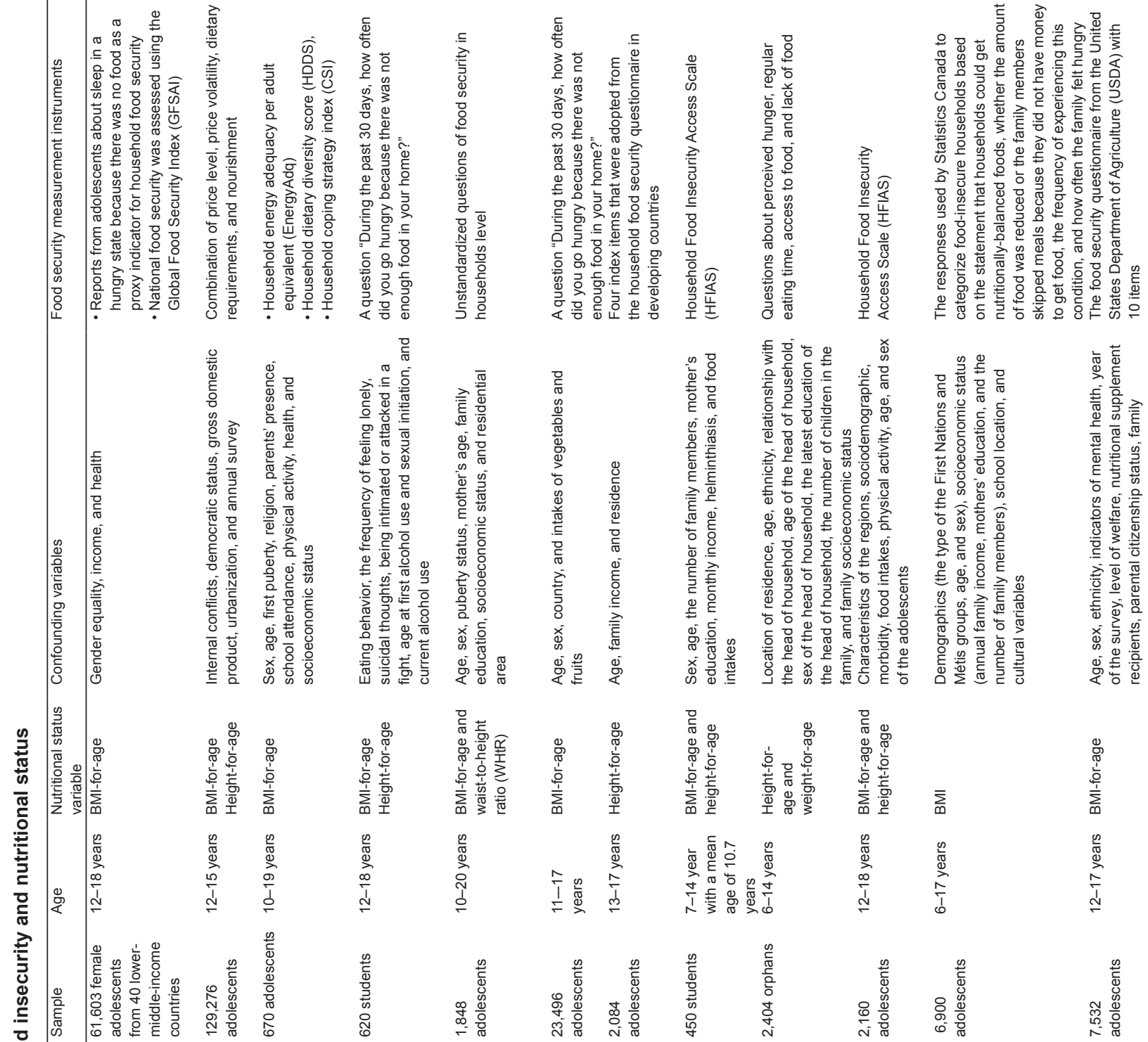

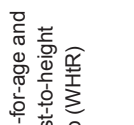

齿帝

言 훙ㅎำ

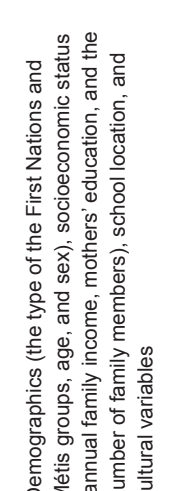

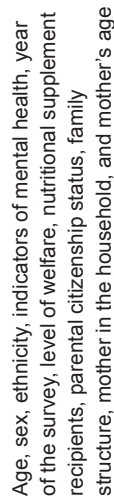

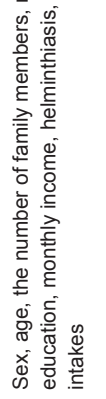

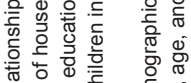

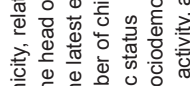

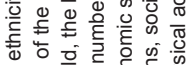

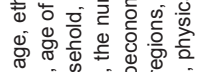

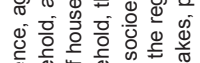

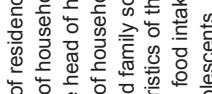

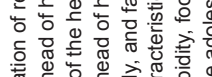

Mำ

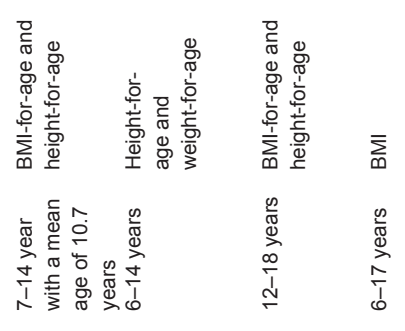

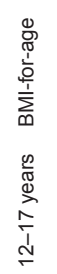

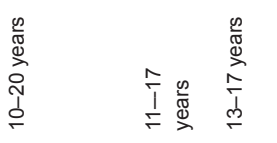

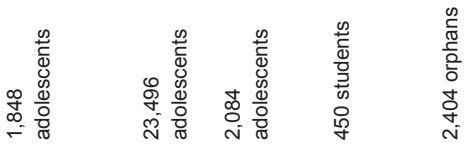

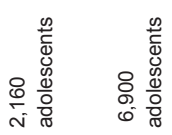

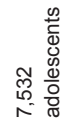
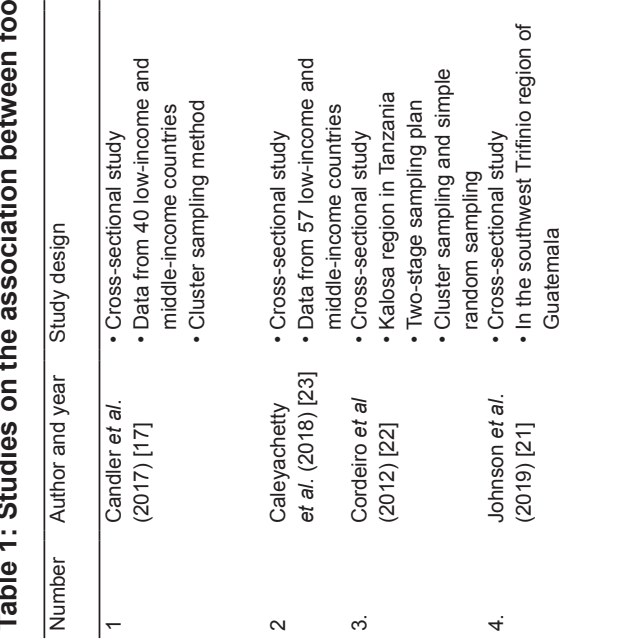

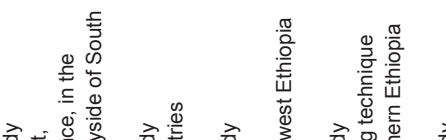

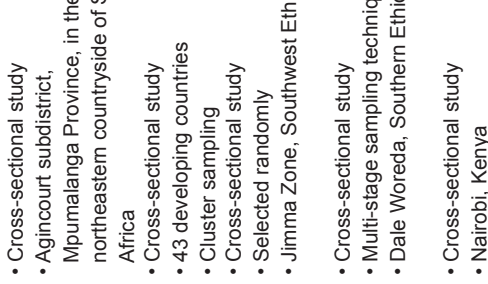

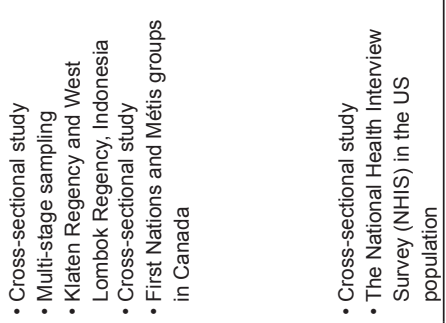

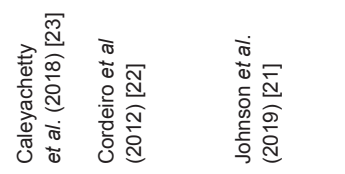

竞离兽

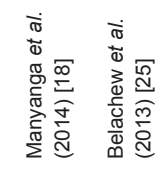

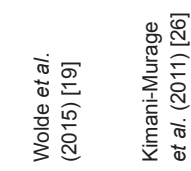

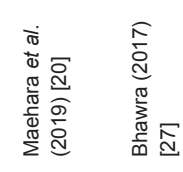

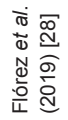


hungry stomach or not as an indicator of household food security levels [17]. In contrast, another study used perceived hunger, regular eating time, access to food, and lack of food as the indicators [26]. A study in Southwest Ethiopia used four index items adopted from the food security questionnaire used in developing countries [25]. A study in Tanzania used a combination of household energy adequacy per adult equivalent (EnergyAdq), Household Dietary Diversity Score (HDDS), and Coping Strategy Index (CSI) [22]. A study on off-reserve First Nations and Métis children and youth used the response of its research subjects to categorize food security in Canada [27]. A study on Latino youth used the food security questionnaire from the United States Department of Agriculture (USDA). A study of low-income and middle-income countries used a combination of the price level, price volatility, dietary requirements, and nourishment as a food security indicator [23]. Another study employed unstandardized questions of food security in households' level [24].

Several confounding factors were included in the analysis in each study to clarify that the association between food insecurity and anthropometry is not shaped by other factors. Nine studies assessed socioeconomic status [17], [19], [20], [22], [24], [25], [26], [27], [28], two studies measured physical activity [20], [22], four studies measured health $(17,19,20,22)$ and four studies assessed food intake [18], [19], [20], [21], [22]. Fruits and vegetables and unhealthy foods such as salty food and high-fat food and sugar-sweetened beverage were assessed using a food frequency questionnaire [18], [20], [21] or a 24-h dietary recall [19].

The review results indicated that food insecurity had a negative correlation with BMl-for-age in three studies out of nine studies that assessed food insecurity using the BMl-for-age indicator (33.3\%). Adolescents from food-insecure households tended to be thinner than those in food-secure households [17], [19], [22]. A study using the WHtR parameter also showed that adolescents from food-insecure households were positively related to a high WHtR [24]. Three of the six studies (50\%) that used the height-for-age indicator showed that food insecurity had a positive correlation with a low heightfor-age (stunting) in adolescents [19], [23], [25]. Five other studies $(55.6 \%)$ showed that food insecurity was not related to BMI-for-age [18], [20], [21], [23], [27] or weight-for-age [26]. Three studies (50\%) also showed no association between food insecurity and height-forage [20], [21], [26].

\section{Discussion}

This review aimed to assess the association between food insecurity and the incidence of malnutrition in adolescents from various studies. This review also showed that only $44.4-50 \%$ of studies indicated a significant association between food insecurity and nutritional status in adolescents using the BMl-forage indicator or height-for-age indicator. The studies indicating no significant association between food insecurity and nutritional status in adolescents in this review were also nearly equal in number.

Foodinsecurityisassociated with thelowquantity and quality of food intake due to compensation for lack of food quantity and lack of food access [29], [30]. The quantity and quality of adolescents' intakes are related to their nutritional status [31], [32]. The low quantity of adolescents' food intake gives a manifestation in the form of poor nutritional status, and the low quality of diet (e.g., monotonous food intake) can give manifestations on the nutritional status in the form of low BMI-for-age and low height-for-age [33], [34]. The quality of diet is related to the adequacy of minerals in adolescents, which is associated with skeletal growth [35]. The quantity and quality of food intakes among adolescents in food-insecure households are lower than those in food-secure households [29].

In this review, it was known that two studies showed that food insecurity had a positive correlation with overweight and obesity [24], [28]. The results of a systematic review in groups of children and adults showed a similar positive correlation [3]. The low quality of diet also causes adolescents in food-insecure households to become fatter or more obese than those in food-secure households. Food-insecure households are easier to obtain high-calorie and low-nutrient foods due to the low prices [36], [37], [38]. Foods, such as vegetables and fruits, are categorized as low-energy groups but quite expensive to be affordable by foodinsecure groups [37]. Food-insecure households also tend to buy food monotonously with little variation as a consequence of low financial conditions [39]. Foods with high-calorie counts cause weight gain more easily if consumed regularly [40].

The association between food insecurity and nutritional status can also be explained through morbidity levels that affect nutritional status. Adolescents in food-insecure households also have a higher risk of having health problems than those in food-secure households [29], [41]. If this condition persists for a long time, it will mainly inhibit the growth of adolescents that will be manifested in height-forage [3]. However, two studies assessing adolescent's health as a confounding variable in this review showed that food security was still related to nutritional status, independent of adolescent's health status [17], [22].

Food security has a negative correlation with household socioeconomic levels [42], [43]. Food-insecure households tend to have low income, large families, poor residence sanitation, and low maternal education [43], [44], [45]. These various socioeconomic factors have positive correlations with undernutrition [46], [47] or overnutrition [48] in 
adolescents. Nine studies in this review involved socioeconomic factors as confounding variables in their analyses [17], [19], [20], [22], [24], [25], [26], [27], [28]. However, the above variables were not analyzed simultaneously in all studies. Two studies showed that the association between food insecurity and obesity became insignificant after incorporating socioeconomic variables into the analysis [20], [27]. One study also showed that the association between food security and stunting disappeared after adjusting for wealth status [20]. Therefore, household socioeconomic conditions can affect the association between food security and nutritional status in adolescents.

In this review, other articles showed that there was no significant association between food security and nutritional status in adolescents [18], [21], [26], [27]. These studies did not include various confounding variables in the analyses that could disrupt the association between food security and adolescent nutrition, such as socioeconomic conditions [18], [21] health conditions [18], and physical activity [21], [26], [27]. An instrument of food security assessment may not capture the differentiation among cultural settings in a study, so that actual food security situation may not be shown [26].

This review indicated that the association between food insecurity and nutritional status of adolescents in various countries still showed mixed results. The limitation of this review was that it could not control various confounding variables that were not assessed and not included in the analyses in several studies. Further research to observe the association between food security and adolescents' nutritional status also needs to be conducted by analyzing food intake, health, policies, socioeconomic conditions, and various food security programs that have been performed.

\section{Conclusion}

The association between food insecurity and anthropometry measurement in adolescents in various regions is still diverse. However, the relationship between food security and malnutrition both over and undernutrition existed in some studies reveals the need to take concern in food security intervention to support nutrition and health in adolescents. Various studies with large sample sizes and longitudinal study design (e.g., Cohort study) need to be conducted to ensure the actual relationship between food insecurity and nutritional status in various regions. Various confounding factors also need to be included in further research related to the conceptual framework that affects food insecurity and nutritional status in adolescents.

\section{Acknowledgment}

We thank Indonesia Endowment Fund for Education (LPDP) for covering the Ph.D. study of the first author, thus make the possibility to the authors to work in this article. We also thank the University of Tadulako for the financial support of the article publication.

\section{References}

1. Food and Agricultural Organization of the United Nations. Rome Declaration on Food Security. Rome: Food and Agricultural Organization of the United Nations; 1996. https:// doi.org/10.1093/ww/9780199540884.013.u33867

2. Murthy VH. Food insecurity: A public health issue. Public Health Rep. 2016;131(5):655-7. PMid:28123203

3. Maitra C. A Review of Studies Examining the Link between Food Insecurity and Malnutrition. Rome: Food and Agriculture Organization of the United Nations; 2018.

4. Dick B, Ferguson BJ. Health for the world's adolescents: Asecond chance in the second decade. J Adolesc Health. 2015:56(1):36. $\quad$ https://doi.org/10.1016/j.jadohealth.2014.10.260 PMid:25530601

5. UNICEF. The State of the World's Children 2011: Adolescence-an Age of Opportunity. New York: UNICEF; 2011.

6. Mramba L, Ngari M, Mwangome M, Muchai L, Bauni E, WalkerAS, et al. A growth reference for mid upper arm circumference for age among school age children and adolescents, and validation for mortality: Growth curve construction and longitudinal cohort study. BMJ. 2017;358:j3423. https://doi.org/10.1136/bmj.j3423 PMid:28774873

7. Spear BA. Adolescent growth and development. J Am Diet Assoc. 2002;102(3):S23-9. PMid:11902385

8. Matkovic V, Jelic T, Wardlaw GM, llich JZ, Goel PK, Wright $\mathrm{JK}$, et al. Timing of peak bone mass in Caucasian females and its implication for the prevention of osteoporosis. Inference from a cross-sectional model. J Clin Invest. 1994;93(2):799-808. https://doi.org/10.1172/jci117034 PMid:8113412

9. Clark CJ, Alonso A, Spencer RA, Pencina M, Williams K Everson-Rose SA. Predicted long-term cardiovascular risk among young adults in the national longitudinal study of adolescent health. Am J Public Health. 2014;104(12):e108$15 . \quad$ https://doi.org/10.2105/ajph.2014.302148 PMid:25322295

10. Inge $T H$, King WC, Jenkins TM, Courcoulas AP, Mitsnefes $M$, Flum DR, et al. The effect of obesity in adolescence on adult health status. Pediatrics. 2013;132(6):1098$104 . \quad$ https://doi.org/10.1542/peds.2013-2185 PMid:24249816

11. Must A, Phillips SM, Naumova EN. Occurrence and timing of childhood overweight and mortality: Findings from the Third Harvard Growth Study. J Pediatr. 2012;160(5):74350. PMid:22183448 https://doi.org/10.1016/j.jpeds.2011.10.037

12. SPRING and Save the Children. Engaging Adolescents to Accelerate Progress on the First 1,000 Days. Arlington: Strengthening Partnerships, Results, and Innovations in Nutrition Globally (SPRING) Project; 2018. 
13. Pinhas-Hamiel O, Reichman B, Shina A, Derazne E, Tzur D, Yifrach D, et al. Sex differences in the impact of thinness, overweight, obesity, and parental height on adolescent height. J Adolesc Health. 2017;61(2):2339. $\quad$ https://doi.org/10.1016/j.jadohealth.2017.02.016 PMid:28457687

14. Elmadfa I, Meyer AL. Developing Suitable methods of nutritional status assessment: A continuous challenge. Adv Nutr. 2014;5(5):590S-8. https://doi.org/10.3945/an.113.005330

15. Gibson RS. Principles of Nutritional Assessment. Oxford: Oxford University Press; 2005.

16. De Onis M, Onyango AW, Borghi E, Siyam A, Nishida C, Siekmann J. Development of a WHO growth reference for school-aged children and adolescents. Bull World Health Organ. 2007;85(9):660-7. https://doi.org/10.2471/blt.07.043497 PMid: 18026621

17. Candler T, Costa S, Heys M, Costello A, Viner RM. Prevalence of thinness in adolescent girls in low- and middle-income countries and associations with wealth, food security, and inequality. J Adolesc Health. 2017;60(4):44754. $\quad$ https://doi.org/10.1016/j.jadohealth.2016.11.003 PMid:28110865

18. Manyanga T, El-Sayed H, Doku DT, Randall JR. The prevalence of underweight, overweight, obesity and associated risk factors among school-going adolescents in seven African countries. BMC Public Health. 2014;14:887. https://doi.org/10.1186/1471-2458-14-887 PMid:25168589

19. Wolde M, Berhan Y, Chala A. Determinants of underweight, stunting and wasting among schoolchildren. BMC Public Health. 2015;15:8. https://doi.org/10.1186/s12889-014-1337-2 PMid:25595201

20. Maehara M, Rah JH, Roshita A, Suryantan J, Rachmadewi A, Izwardy D. Patterns and risk factors of double burden of malnutrition among adolescent girls and boys in Indonesia. PLoS One. 2019;14(8):e0221273. https://doi.org/10.1371/journal.pone.0221273 PMid:31430324

21. Johnson RK, Lamb $M$, Anderson $H$, Pieters-Arroyo $M$, Anderson BT, Bolaños GA, et al. The global school-based student health survey as a tool to guide adolescent health interventions in rural Guatemala. BMC Public Health. 2019;19(1):226. https://doi. org/10.1186/s12889-019-6539-1

22. Cordeiro LS, Wilde PE, Semu H, Levinson FJ. Household food security is inversely associated with undernutrition among adolescents from Kilosa, Tanzania. J Nutr. 2012;142(9):1741-7. https://doi.org/10.3945/jn.111.155994 PMid:22810984

23. Caleyachetty R, Thomas GN, Kengne AP, Echouffo-Tcheugui JB, Schilsky S, Khodabocus J, et al. The double burden of malnutrition among adolescents: Analysis of data from the global schoolbased student health and health behavior in school-aged children surveys in 57 low- and middle-income countries. Am J Clin Nutr. 2018;108(2):414-24. https://doi.org/10.1093/ajcn/nqy105 PMid:29947727

24. Kimani-Murage EW. Exploring the paradox: Double burden of malnutrition in rural South Africa. Glob Health Action. 2013;6:19249. https://doi.org/10.3402/gha.v6i0.19249 PMid:23364082

25. Belachew T, Lindstrom D, Hadley C, Gebremariam A, Kasahun W, Kolsteren P. Food insecurity and linear growth of adolescents in Jimma Zone, Southwest Ethiopia. Nutr J. 2013;12(1):55. https://doi.org/10.1186/1475-2891-12-55

26. Kimani-Murage EW, Holding PA, Fotso JC, Ezeh AC, Madise NJ, Kahurani EN, et al. Food security and nutritional outcomes among urban poor orphans in Nairobi, Kenya. J Urban Health. 2011;88 Suppl 2(Suppl 2):S282-97. https://doi.org/10.1007/s11524-010-9491-z

\section{PMid:20945109}

27. Bhawra J, Cooke MJ, Guo Y, Wilk P. The association of household food security, household characteristics and school environment with obesity status among off-reserve first nations and métis children and youth in Canada: Results from the 2012 Aboriginal Peoples Survey. Health Promot Chronic Dis Prev Can. 2017;37(3):77-86. https://doi.org/10.24095/hpcdp.37.3.03 PMid:28273035

28. Flórez KR, Katic BJ, López-Cevallos DF, Murillo $R$, Cancel-Tirado D, Aponte-Soto L, et al. The double burden of food insecurity and obesity among Latino youth: Understanding the role of generational status. Pediatr Obes. 2019;14(9):e12525. https://doi.org/10.1111/ijpo.12525 PMid:31022773

29. Eicher-Miller HA, Zhao Y. Evidence for the age-specific relationship of food insecurity and key dietary outcomes among US children and adolescents. Nutr Res Rev. 2018;31(1):98113. https://doi.org/10.1017/s0954422417000245 PMid:29318982

30. Tariku A, Gonete KA, Bikes GA, Alemu K, Belew AK, Wassie MM, et al. Household food insecurity predisposes to undiversified diet in northwest Ethiopia: Finding from the baseline survey of nutrition project, 2016. BMC Res Notes. 2019;12(1):54. https:// doi.org/10.1186/s13104-019-4083-9

31. Assumpção D, Barros MB, Fisberg RM, Carandina L, Goldbaum M, Cesar CL. Qualidade da dieta de adolescentes: Estudo de base populacional em Campinas, SP. Rev Bras Epidemiol. 2012;15(3):605-16. https://doi.org/10.1590/ s1415-790x2012000300014

32. Malhotra A, Passi SJ. Diet quality and nutritional status of rura adolescent girl beneficiaries of ICDS in North India. Asia Pac J Clin Nutr. 2007;16 Suppl 1:8-16.

33. Gutiérrez-Pliego LE, Camarillo-Romero ES, MontenegroMorales LP, Garduño-García JJ. Dietary patterns associated with body mass index (BMI) and lifestyle in Mexican adolescents. BMC Public Health. 2016;16(1):850. https://doi.org/10.1186/ s12889-016-3527-6

34. Doustmohammadian A. Nutritional status and dietary intake among adolescent girls. J Paramed Sci. 2013;4:72-7.

35. Fang A, Li K, Li H, Guo M, He J, Shen X, et al. Low habitual dietary calcium and linear growth from adolescence to young adulthood: Results from the China Health and Nutrition Survey. Sci Rep. 2017;7(1):9111. https://doi.org/10.1038/s41598-017-08943-6 PMid:28831091

36. Ludwig DS, Pollack HA. Obesity and the economy: From crisis to opportunity. JAMA. 2009;301(5):533-5. https://doi.org/10.1001/ jama.2009.52

37. Drewnowski A, Specter S. Poverty and obesity: The role of energy density and energy costs. Am J Clin Nutr. 2004;79(1):6-16. PMid:14684391

38. Rao M, Afshin A, Singh G, Mozaffarian D. Do healthier foods and diet patterns cost more than less healthy options? A systematic review and meta-analysis. BMJ Open. 2013;3(12):e004277. https://doi.org/10.1136/bmjopen-2013-004277

39. O'Brien M. Poverty, Policy and the State: The Changing Face of Social Security. Bristol: Policy Press; 2007.

40. Yin J, Xue HM, Chen YY, Zhang X, Quan LM, Gong YH, et al. Dietary energy density is positively associated with body composition of adults in Southwest China. Public Health Nutr. 2018;21(10):1827-34. https://doi.org/10.1017/ s1368980018000277

41. Gundersen C, Ziliak JP. Food insecurity and health outcomes. Health Aff (Millwood). 2015;34(11):1830$9 . \quad$ https://doi.org/10.1377/hlthaff.2015.0645 PMid:26526240

42. Nagata JM, Fiorella $\mathrm{KJ}$, Salmen CR, Hickey MD, Mattah $\mathrm{B}$, Magerenge $\mathrm{R}$, et al. Around the table: Food 
insecurity, socioeconomic status, and instrumental social support among women living in a rural Kenyan Island Community. Ecol Food Nutr. 2015;54(4):35869. https://doi.org/10.1080/03670244.2014.995790 PMid:25680030

43. Mortazavi Z, Dorosty AR, Eshraghian MR, Ghaffari M, AnsariMoghaddam A, Mohammadi M. Household food insecurity in Southeastern Iran: Severity and related factors. Int J Food Sci. 2017;2017(12):1-7. https://doi.org/10.1155/2017/7536024

44. Ali B, Nasrin A, Parvin S, Azam J. The relationship between food security, dietary patterns, and socioeconomic status in Iranian pregnant women. Prog Nutr. 2019;21(1-S):261-9.

45. Nkomoki W, Bavorová M, Banout J. Factors associated with household food security in Zambia. Sustainability. 2019;11(9):2715. https://doi.org/10.3390/su11092715
46. Assefa $\mathrm{H}$, Belachew $\mathrm{T}$, Negash L. Socio-demographic factors associated with underweight and stunting among adolescents in Ethiopia. Pan Afr Med J. 2015;20:252. https://doi.org/10.11604/pamj.2015.20.252.3588 PMid:26161175

47. Radhika MS, Swetha B, Kumar BN, Krishna NB, Laxmaiah A Dietary and nondietary determinants of nutritional status among adolescent girls and adult women in India. Ann N Y Acad Sci. 2018;1416(1):5-17. https://doi.org/10.1111/ nyas.13599

48. Newton S, Braithwaite D, Akinyemiju TF. Socio-economic status over the life course and obesity: Systematic review and meta-analysis. PLoS One. 2017;12(5):e0177151. https://doi.org/10.1371/journal.pone.0177151 PMid:28510579 